\title{
Prospecção Tecnológica Sobre Enxaguatório Bucal com Potencial Clareador
}

\author{
Technological Prospection on Mouthwash With Whitening Potential
}

\author{
Brenda de Oliveira ${ }^{1}$ \\ Mateus Freire Leite ${ }^{1}$ \\ ${ }^{1}$ Universidade Federal de Alfenas, Alfenas, MG, Brasil
}

\begin{abstract}
Resumo
Os enxaguatórios bucais começaram a ser utilizados há cerca de 219 anos devido à grande dificuldade de higienização oral mecânica e, nos últimos, vêm sendo amplamente utilizados por razões cosméticas e sociais. Em sua maioria, eles possuem efeito bactericida principalmente frente a Streptococcus sp. Uma outra vertente da sua utilização é a aplicação de tecnologias em sua formulação que, concomitante ao seu uso, gerem clareamento da coloração dentária. Com o objetivo de obter dados numéricos e históricos sobre patentes relacionadas a enxaguatórios bucais com potencial clareador, uma prospecção tecnológica foi realizada. Utilizando a base de dados Espacenet, percebeuse que os Estados Unidos e a China possuem o maior número de inovações referentes ao uso de enxaguatórios bucais, porém esse uso se mostra ainda pouco explorado devido ao baixo número de tecnologias relacionadas a ele. O Brasil não possui patentes depositadas sobre enxaguatórios bucais com potencial clareador, porém, com o seu crescente consumo, isso pode vir a mudar.
\end{abstract}

Palavras-chave: Enxaguatório bucal. Clareador Dental. Prospecção Tecnológica.

\begin{abstract}
The mouthwashes began to be used 219 years ago, due to the big difficulty of mechanical oral hygiene. In recente years, it has been widely used for cosmetic and social reasons. Most have bactericidal effect mainly against Streptococcus sp. Another aspect of the use is the application of technologies in it's formulation, which concomitante with the use generate whitening of dental color. In order to obtain numerical and historical data on patents related to mouthwash with bleaching potential, a technological prospection was performed. Using Espacenet database, it was noticed that the United States and China have the largest number of innovations related to this technology, but it is still underexplored due to the low number of technologies. Brazil does not have patents filed on mouthwashes with whitening potential, but with the increasing consumption of mouthwashes, this may change.
\end{abstract}

Keywords: Mouthwash. Teeth Whitening. Technological Prospection.

Área Tecnológica: Cosméticos. 


\section{Introdução}

A utilização de enxaguatórios bucais foi iniciada em meados de 1800 e se consolidou com o tempo devido às dificuldades dos métodos de higiene oral mecânica, como as escovas de dente, pois são de uso fácil, são refrescantes, têm palatabilidade e podem chegar às bactérias mesmo em áreas de maior dificuldade (ASADOORIAN, 2006; LIMA JÚNIOR et al., 2005; JARDIM; JARDIM, 1998).

Nos anos 2000, o uso dos enxaguatórios bucais já vinha se tornando mais popular por razões sociais e cosméticas, encontrando-se em ascensão no Brasil como complemento da higiene oral feita com escova e dentifrícios, representando um meio mais simples de veiculação de substâncias antissépticas, sendo uma mistura do componente ativo, água, álcool, surfactantes, umectantes e flavorizantes (TORRES et al., 2000).

Um levantamento realizado pela Mintel (2019) sobre o mercado de enxaguatórios bucais revelou que o enxaguatório bucal está sendo muito bem aceito pela população e mostrou que nos Estados Unidos as vendas cresceram 15\% entre 2012 a 2017, acima da taxa total do mercado, que era de $13,6 \%$.

Conforme prevê a Resolução RDC n. 07/2015, produtos de higiene pessoal, cosméticos e perfumes são preparações constituídas por substâncias naturais ou sintéticas, de uso externo nas diversas partes do corpo humano, pele, sistema capilar, unhas, lábios, órgãos genitais externos, dentes e membranas mucosas da cavidade oral, com o objetivo exclusivo ou principal de limpá-los, perfumá-los, alterar sua aparência e ou corrigir odores corporais e ou protegê-los ou mantê-los em bom estado.

De acordo com o seu grau de risco, ou seja, probabilidade de ocorrência de efeitos não desejados devido ao uso inadequado do produto, sua formulação, finalidade de uso, áreas do corpo a que se destinam, existem dois grupos:

Produtos Grau 1: são produtos de higiene pessoal, cosméticos e perfumes cuja formulação cumpre com as definições da Resolução e que se caracterizam por possuírem propriedades básicas ou elementares, cuja comprovação não seja inicialmente necessária e não requeiram informações detalhadas quanto ao seu modo de usar e suas restrições de uso, devido às características intrínsecas do produto.

Produtos Grau 2: são produtos de higiene pessoal, cosméticos e perfumes cuja formulação cumpre com as definições da Resolução e que possuem indicações específicas, cujas características exigem comprovação de segurança e/ou eficácia, bem como informações e cuidados, modo e restrições de uso.

Geralmente, a eficácia dos antissépticos orais é atribuída à sua atividade bactericida, preferencialmente em produtos de efeito intraoral prolongado, definida como substantividade ou habilidade de um agente ativo de colar na superfície do tecido a ser tratado e de ser liberado com o tempo, provendo atividade antibacteriana sustentada (ASADOORIAN, 2006).

Os diversos enxaguatórios auxiliam no combate às bactérias causadoras das afecções bucais mais comuns, como a cárie dentária, a placa, o tártaro, a gengivite e a periodontite, que é uma infecção gengival grave e, ainda, causadora do mau hálito. Os agentes etiológicos principais da placa dentária são os Streptococcus sp. (cocos Gram-positivos) e Actinomices sp. (bacilos Gram-negativos). A característica da placa é de contínua agressão, que vai adquirindo novas 
espécies de microorganismos como o S. miti, S. sagüis, S. sobrinus, S. mutans e Lactobacillus em cada etapa de seu desenvolvimento. A placa dentária inicia com a instalação de bactérias orais, podendo ser de natureza patogênica ou não, que aderem à película dental, derivada de produtos bacterianos e da saliva que se formam sobre os dentes. A placa é considerada fator chave de contribuição para a inflamação gengival que, se não tratada, pode progredir para a periodontite (ASADOORIAN, 2006; LIMA JÚNIOR et al., 2005; FDA, 2003; SOUZA; GIL, 1998; GEBARA; ZARDETTO; MAYER, 1996).

Outro seguimento dos produtos de higiene oral é o daqueles com potencial clareador, pois alterações na coloração dentária são relativamente comuns, e a procura de produtos não-invasivos para clarear os dentes por questões estéticas vem crescendo. Essa demanda gerou pesquisa e desenvolvimento de diferentes materiais e técnicas de clareamento capazes de restabelecer a cor sem afetar a estrutura dentária.

Sendo assim, o presente estudo propôs realizar uma prospecção tecnológica sobre enxaguatórios bucais com potencial clareador e com o intuito de identificar quantitativamente e qualitativamente artigos nessa área.

\section{Metodologia}

O estudo em questão foi desenvolvido por meio de pesquisa prospectiva por patentes relacionadas a enxaguatórios bucais com potencial clareador. Utilizou-se como fonte de pesquisa o Espacenet, disponibilizado pelo Escritório Europeu de Patentes, que é uma base de dados internacional.

Foram realizadas combinações de diferentes palavras-chave para localizar o maior número de patentes possível por meio do título e do resumo de cada uma, abrangendo assim os mais diferentes tipos de pesquisa dentro do tema. Tais termos foram: mouth, oral, wash, rins*, white*, bleach*, tooth, teeth e dental. O asterisco $\left({ }^{*}\right)$ nas palavras simboliza que o termo pode vir a ter diferentes terminações. O escopo da prospecção é apresentado na Quadro 1.

A coleta de dados foi realizada no período de abril a junho de 2019, e os resultados foram exportados por ferramenta de banco de dados e processados para o Microsoft Office Excel 2010.

A partir dos documentos recuperados, foram excluídos os arquivos duplicados e os que estavam fora do escopo da prospecção.

Os documentos foram tratados no Microsoft Excel 2010, analisando-se:

a) A tendência histórica pelo ano de depósito das patentes.

b) A localidade, país dos depositantes.

c) As empresas ou inventores independentes que realizaram o depósito da patente.

d) Os inventores da tecnologia.

e) A Classificação Internacional de Patentes (IPC). 
Quadro 1 - Escopo da pesquisa para busca de patentes relacionadas a enxaguatório bucal com potencial clareador

\begin{tabular}{|c|c|c|c|c|c|c|c|c|c|c|}
\hline \multicolumn{9}{|c|}{ Palavras-chave } & \multirow{2}{*}{\multicolumn{2}{|c|}{ FORMAÇÃO: }} \\
\hline MoutH & Oral & WASH & Rins* & WHITE* & BlEACH* & Тоотн & ТеEтH & Dental & & \\
\hline $\mathrm{X}$ & & & $\mathrm{X}$ & & & & & & Mouthrins* & Mouth rins* \\
\hline \multirow[t]{22}{*}{$\mathrm{X}$} & & $\mathrm{X}$ & & & & & & & Mouthwash & Mouth wash \\
\hline & $\mathrm{X}$ & & & & $\mathrm{X}$ & & & & Oral bleach* & \\
\hline & $\mathrm{X}$ & $\mathrm{X}$ & & & & & & & Oral wash & \\
\hline & $\mathrm{X}$ & & $\mathrm{X}$ & & & & & & Oral rins* & \\
\hline & $\mathrm{X}$ & & & $\mathrm{X}$ & & & & & Oral white* & \\
\hline & & $\mathrm{X}$ & & $\mathrm{X}$ & & & & $\mathrm{X}$ & White* dental wash & \\
\hline & & & $\mathrm{X}$ & $\mathrm{X}$ & & & & & White* rins* & \\
\hline & & & & & $\mathrm{X}$ & $\mathrm{X}$ & & & Tooth bleach* & \\
\hline & & & & & $\mathrm{X}$ & & $\mathrm{X}$ & & Teeth bleach* & \\
\hline & & & & & $\mathrm{X}$ & & & $\mathrm{X}$ & Dental bleach* & \\
\hline & & $\mathrm{X}$ & & & & & & $\mathrm{X}$ & Dental wash & \\
\hline & $\mathrm{X}$ & & $\mathrm{X}$ & & $\mathrm{X}$ & & & & Oral bleach* rins* & \\
\hline & $\mathrm{X}$ & $\mathrm{X}$ & & & $\mathrm{X}$ & & & & Oral bleach* wash & \\
\hline & $\mathrm{X}$ & $X$ & & $\mathrm{X}$ & & & & & Oral white* wash & \\
\hline & & $\mathrm{X}$ & & & & $\mathrm{X}$ & & & Tooth wash & \\
\hline & & $\mathrm{X}$ & & & & & $\mathrm{X}$ & & Teeth wash & \\
\hline & & $\mathrm{X}$ & & $\mathrm{X}$ & & & $\mathrm{X}$ & & White* teeth wash & \\
\hline & & $\mathrm{X}$ & & $\mathrm{X}$ & & $\mathrm{X}$ & & & White* tooth wash & \\
\hline & & & $\mathrm{X}$ & & & & & $\mathrm{X}$ & Dental rins* & \\
\hline & & & $\mathrm{X}$ & & & $\mathrm{X}$ & & & Tooth rins* & \\
\hline & & & $\mathrm{X}$ & & & & $\mathrm{X}$ & & Teeth rins* & \\
\hline & $\mathrm{X}$ & & $\mathrm{X}$ & $\mathrm{X}$ & & & & & Oral white* rins* & \\
\hline \multirow[t]{14}{*}{$\mathrm{X}$} & & & & $\mathrm{X}$ & & & & & White* mouthrins* & White* mouth rins* \\
\hline & & & & $\mathrm{X}$ & $\mathrm{X}$ & $\mathrm{X}$ & & & $\begin{array}{l}\text { White* tooth } \\
\text { bleach* }\end{array}$ & \\
\hline & & & $\mathrm{X}$ & $\mathrm{X}$ & & $\mathrm{X}$ & & & Tooth white* rins* & \\
\hline & & & $\mathrm{X}$ & $\mathrm{X}$ & & & $\mathrm{X}$ & & Teeth white* rins* & \\
\hline & & & & & $\mathrm{X}$ & & & $\mathrm{X}$ & Dental bleach* & \\
\hline & & $\mathrm{X}$ & & & & & & $\mathrm{X}$ & Dental wash & \\
\hline & & $\mathrm{X}$ & & & $\mathrm{X}$ & & & & Wash bleach* & \\
\hline & & & & $\mathrm{X}$ & $\mathrm{x}$ & & & & White* bleach* & \\
\hline & & $\mathrm{X}$ & & $\mathrm{X}$ & $X$ & & & & $\begin{array}{l}\text { White* bleach* } \\
\text { wash }\end{array}$ & \\
\hline & & & & $\mathrm{X}$ & & & $\mathrm{X}$ & & $\begin{array}{l}\text { White* teeth } \\
\text { bleach* }\end{array}$ & \\
\hline & & & $\mathrm{X}$ & & $\mathrm{X}$ & & & $\mathrm{X}$ & Dental bleach* rins* & \\
\hline & & $X$ & & & $X$ & & & $\mathrm{X}$ & $\begin{array}{l}\text { Dental bleach* } \\
\text { wash }\end{array}$ & \\
\hline & & & & $\mathrm{X}$ & & & & $\mathrm{X}$ & Dental white* wash & \\
\hline & & & $\mathrm{X}$ & $\mathrm{X}$ & & & & $\mathrm{X}$ & Dental white* rins* & \\
\hline
\end{tabular}

Fonte: Elaborado pelos autores deste artigo 


\section{Resultados e Discussão}

Da coleta de dados realizada, selecionaram-se 515 documentos referentes às combinações em negrito na Quadro 1, sendo, White* dental wash referente à: 6 documentos, Oral bleach* rins*: 7 documentos, Oral bleach* wash: 1 documento, Oral white* wash: 22 documentos, White* teeth wash: 15 documentos, White* tooth wash: 10 documentos, Oral white* ${ }^{*}$ rins*: 38 documentos, White* mouthrins*: 6 documentos, White* mouth rins*: 76 documentos, White* tooth bleach*: 155 documentos, Tooth white* rins*: 35 documentos, Teeth white* rins*: 45 documentos, White* bleach* wash: 75 documentos, Dental bleach* rins*: 7 documentos, Dental white* wash: 6 documentos, Dental white* rins*: 11 documentos.

Todas as 515 patentes foram encontradas no Espacenet.

A partir dos 515 documentos recuperados, foi realizada uma análise qualitativa, excluindo-se arquivos duplicados e também os documentos fora do escopo da prospecção, obtendo-se 53 documentos.

Das 53 patentes selecionadas, pode-se observar no Gráfico 1 um aumento de depósitos no ano atual.

Gráfico 1 - Evolução dos depósitos de patentes relacionados a enxaguatórios bucais com potencial clareador a partir de 1952 até os dias atuais encontrados no Espacenet

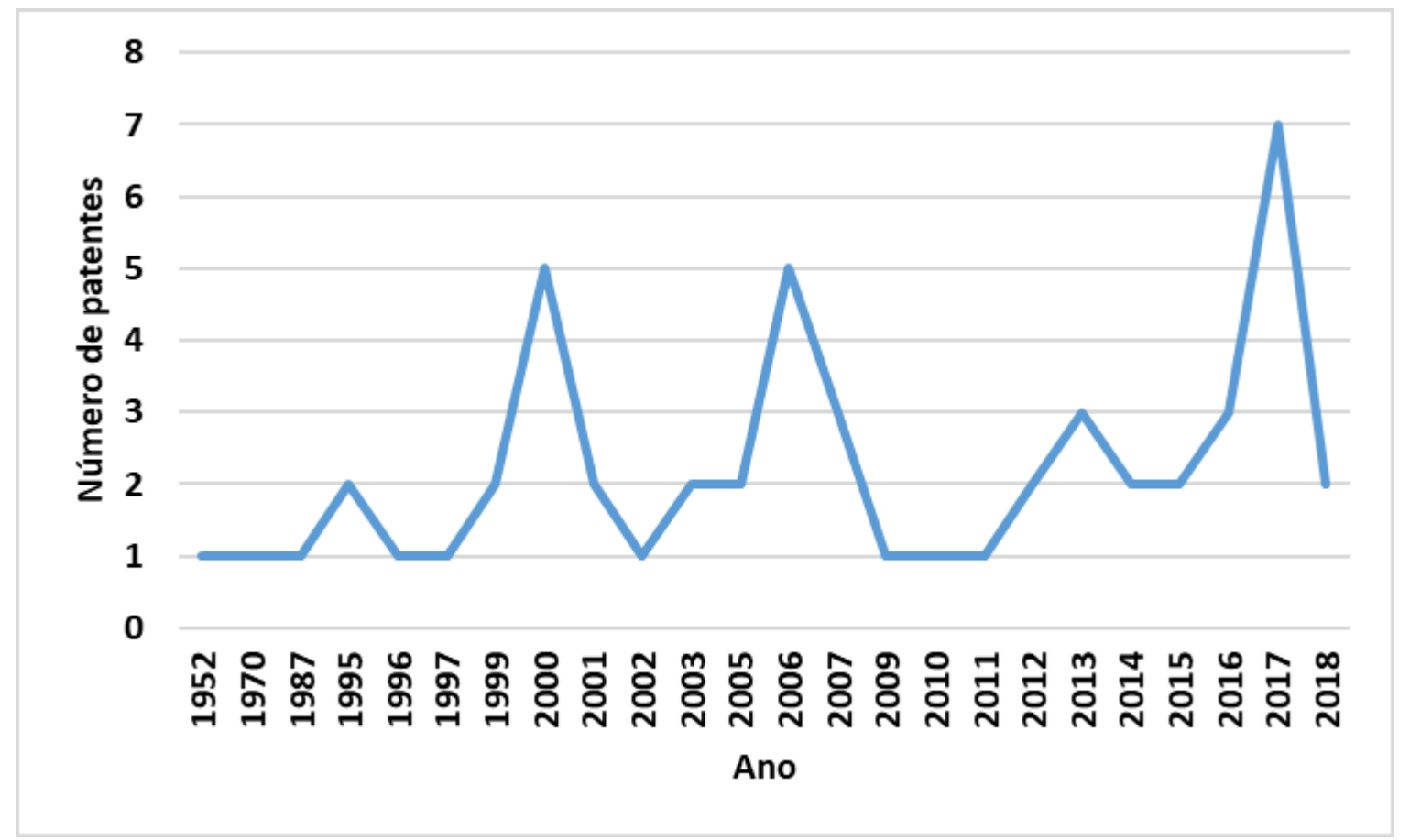

Fonte: Elaborado pelos autores deste artigo

Esse aumento com o decorrer do tempo não foi de maneira linear. Durante os anos houve quedas e picos, com destaque para os anos de 2000 e 2006, os quais tiveram cinco documentos depositados em cada um, enquanto o ano de 2002, entre eles, teve apenas um depósito. 
O ano de 2017 foi o que possuiu o maior número de registros de patentes com esse tipo de tecnologia, sendo sete no total.

Pelos dados do Gráfico 1, é possível concluir que esse tipo de tecnologia ainda não está sendo muito bem explorada, porém os enxaguatórios bucais com composições mais naturais, de acordo com o Caderno de Tendências 2019-2020 da ABIHPEC (2019) e o SEBRAE (GHACHACHE, 2019), vêm apresentando perspectivas de crescimento devido às gerações Millennial e $Z$.

No Gráfico 2 estão apresentados os países com maior depósito de patentes relacionadas a esse estudo.

Gráfico 2 - Países com depósito das patentes relacionadas a enxaguatórios bucais com potencial clareador desde o ano 1952 até atualmente

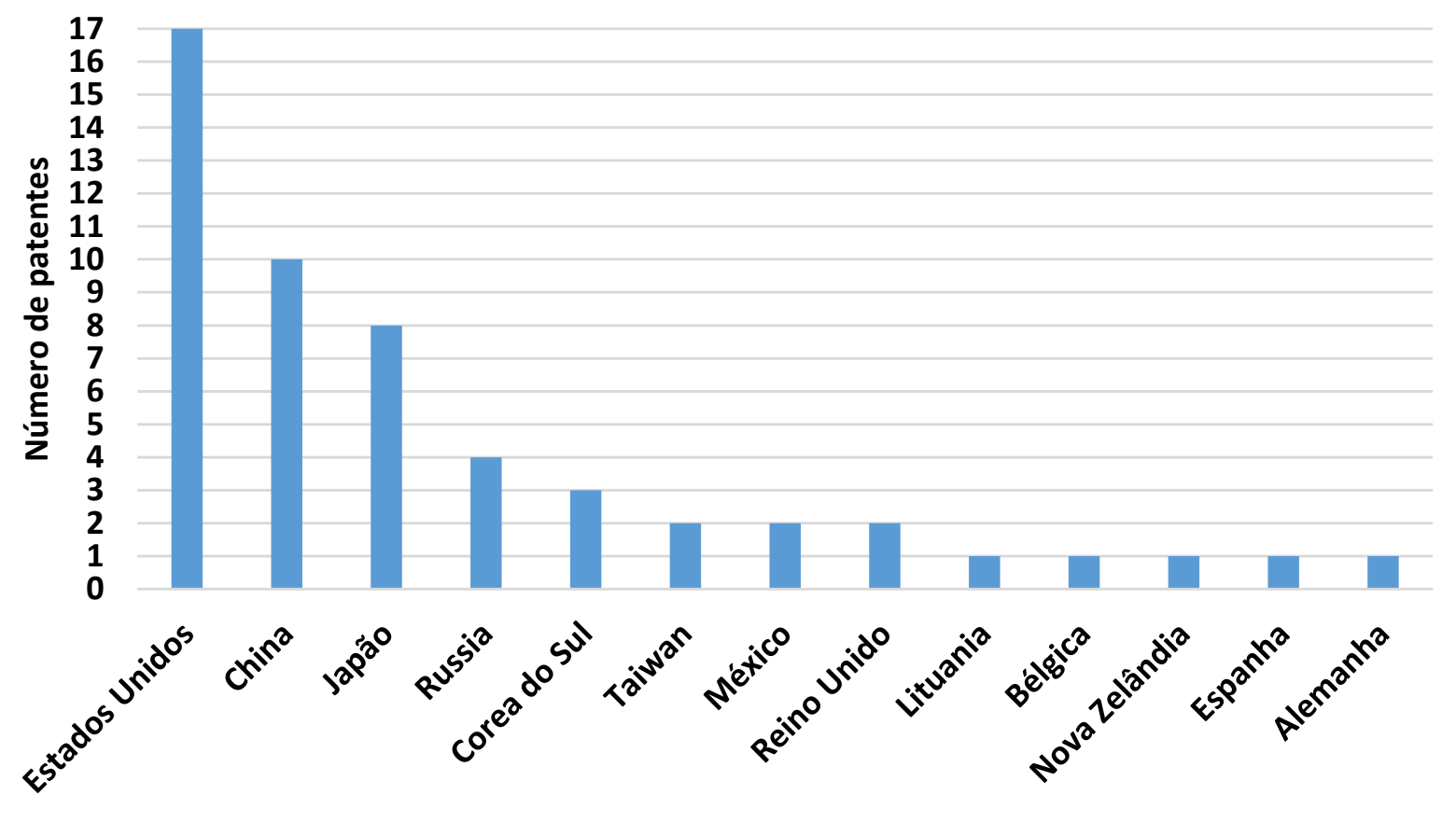

Localidade

Fonte: Elaborado pelos autores deste artigo

Pode-se observar, quantitativamente, que o país com maior número de patentes é os Estados Unidos (EUA), contando com um somatório de 17 depósitos.

Em sequência, vem a China, com 10 documentos, ficando assim em segunda posição, e não muito longe, em terceiro lugar, está o Japão, com oito patentes.

A China e os EUA são grandes potências detentoras de tecnologia, o que propicia um maior número de pesquisas $e$ avanços em diversas áreas, $e$ inclusive na tecnologia de cosméticos $e$ higiene pessoal. Além disso, possuem um grande mercado consumidor no ramo.

De acordo com a ABIHPEC (2019), em 2011, os Estados Unidos concentravam a maior parcela do consumo de produtos de beleza, atingindo $14,8 \%$ do total, contudo essa participação tem se retraído ao longo da última década e a China tem despontado em relação aos mercados tradicionais e consolidados.

Os resultados apresentados no Gráfico 3 estão relacionados ao número de patentes por depositante. 
Gráfico 3 - Titulares que mais depositaram patentes sobre a tecnologia no Espacenet, de 1952 até 2019

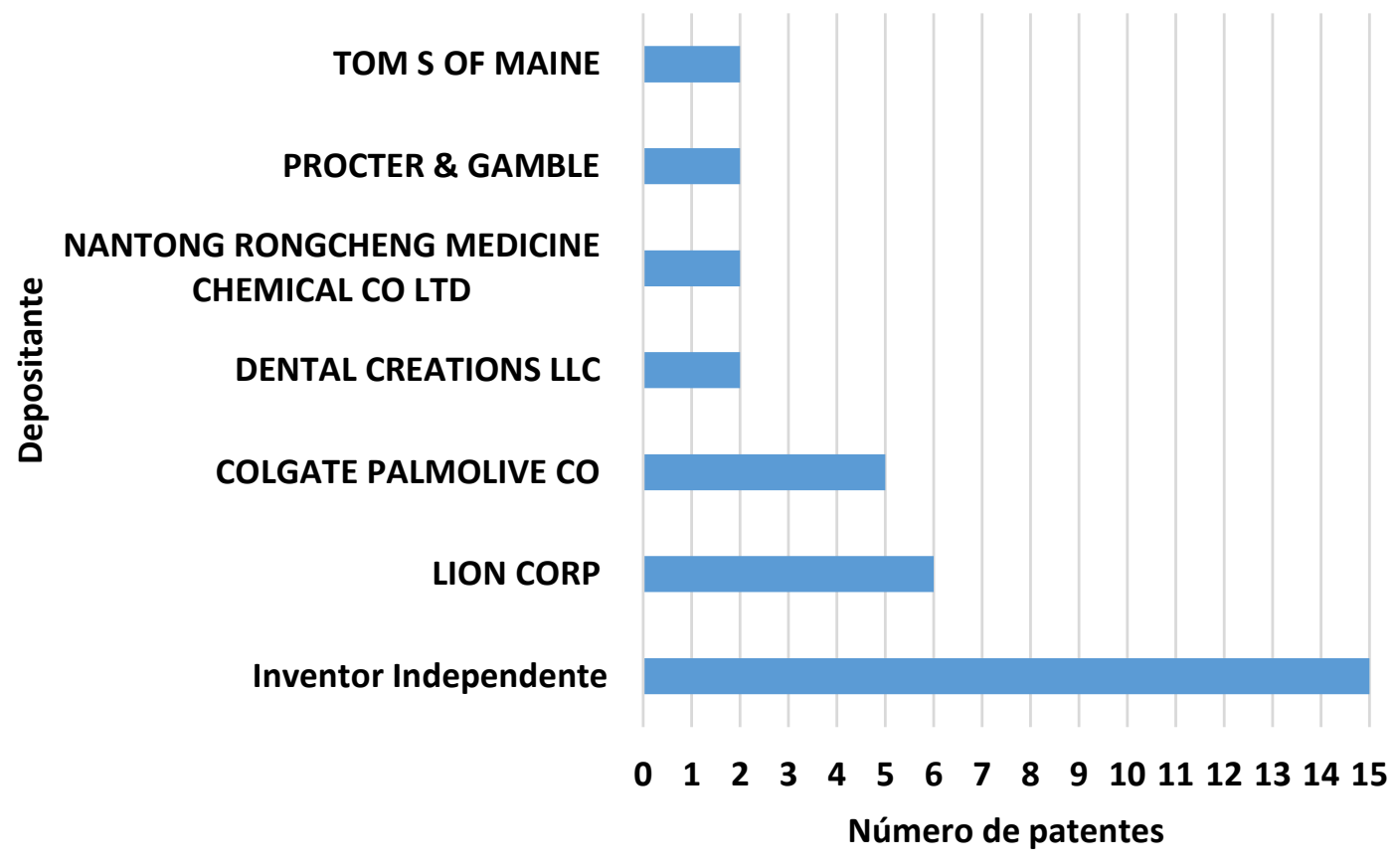

Fonte: Elaborado pelos autores deste artigo

No Gráfico 3 estão apresentados os depositantes com duas ou mais patentes, removendo-se os que possuem apenas uma. De acordo com a análise dos dados do gráfico, pode-se observar que o maior número de patentes depositadas foi de inventores independentes, totalizando 15 patentes, ou seja, não foram empresas ou companhias do ramo de higiene pessoal. Isso mostra que é pequeno o número de grandes empresas que estão fazendo investimentos nesse tipo de tecnologia.

A Lion Corporation, companhia que lidera e tem a maior posição na detenção desse tipo de tecnologia, aparece com seis patentes. É uma empresa japonesa que possui área de desenvolvimento de novos produtos relacionados à higiene oral.

Com cinco patentes, a Colgate-Palmolive tem muita força no mercado, e no quarto trimestre de 2018 registrou um aumento de $87 \%$ no lucro líquido, de acordo com o site Valor.

Possuindo duas patentes cada, aparecem as companhias Nantong Rongcheng Medicine Chemical Co Ltd, Dental Creations Llc, Tom's of Maine e Procter \& Gamble.

Tom's of Maine é uma companhia norte-americana criada com o intuito de introduzir no mercado produtos naturais, sem corantes artificiais, sabores, conservantes e fragrâncias. De acordo com a página on-line da Colgate-Palmolive, em 2006, Tom's of Maine virou parte da Colgate, mas nunca perdeu seus ideais.

Muito conhecida, a Procter \& Gamble $(\mathrm{P} \& \mathrm{G})$ é uma corporação multinacional voltada para saúde pessoal/saúde do consumidor e produtos de cuidados pessoais e higiene. Apesar de quedas em seu histórico, a empresa é líder em pesquisa e desenvolvimento, investindo bilhões em novas fórmulas, de acordo com o EUROMONITOR (2015).

Um fato interessante sobre os depositantes é não ter aparecido nenhuma universidade com duas ou mais patentes sobre o assunto. Apenas uma das 53 patentes é de uma faculdade: a Universidade lles Balears, na Espanha. 
De acordo com os inventores das tecnologias patenteadas, foi possível elaborar um ranking, exposto no Gráfico 4.

Gráfico 4 - Ranking dos inventores que depositaram duas ou mais patentes sobre o tema

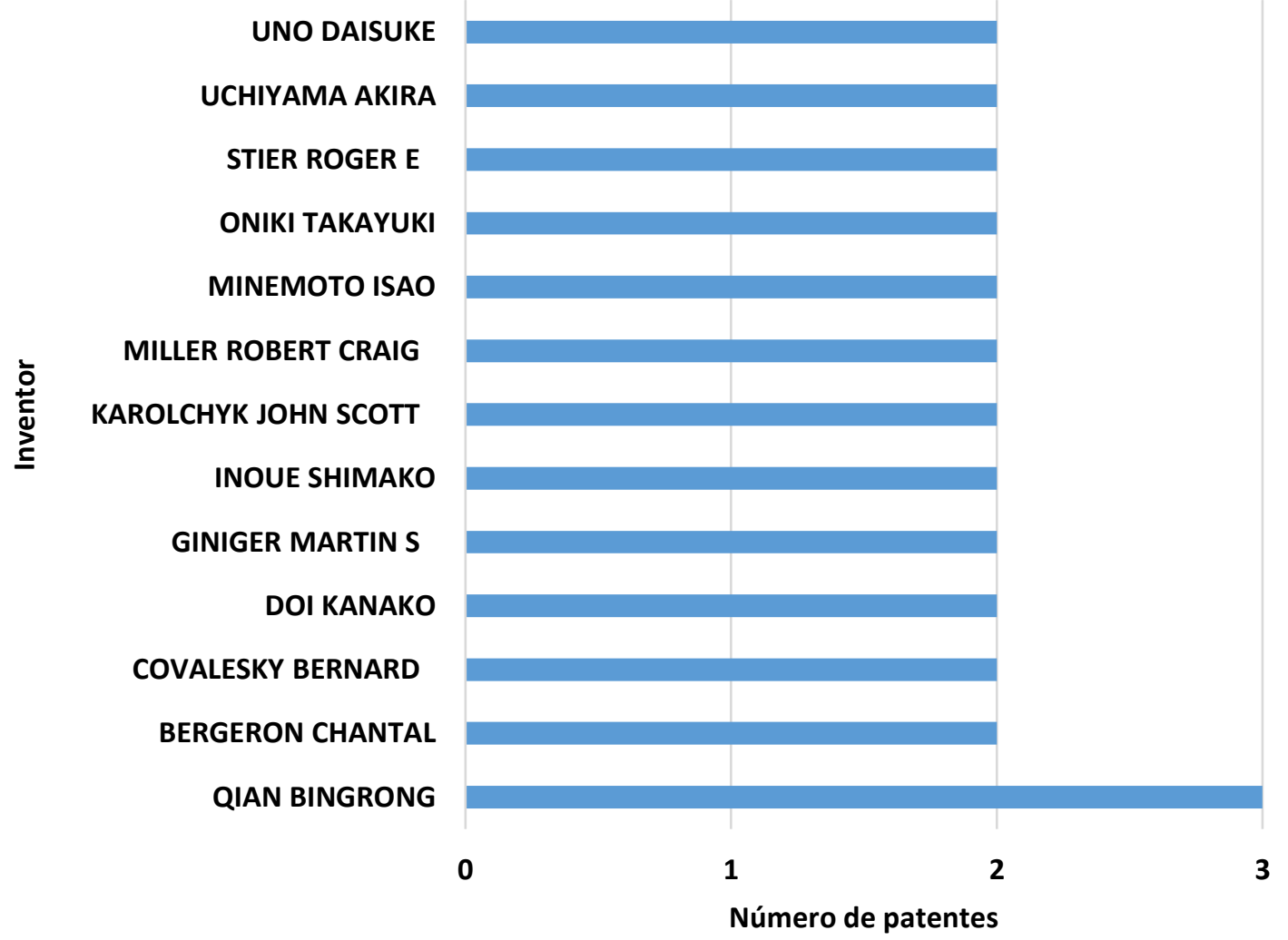

Fonte: Elaborado pelos autores deste artigo

Por meio da observação do Gráfico 4, pode-se concluir que Qian Bingrong se sobressai com três patentes, frente aos outros, com duas. Ele é o presidente da Nantong Hongzhi Chemicals Co., Ltd., especializada em intermediários farmacêuticos e pesticidas, e localizada na China. Os principais produtos são: agente redutor de hidrogenação de alta qualidade, boro-hidreto de potássio, boro-hidreto de sódio, intermediário farmacêutico e éster de ácido bórico. Seus produtos são exportados para Alemanha, Coreia, Índia e Japão, entre outros países. O objetivo da companhia é inovação tecnológica, superar o avançado.

Outro parâmetro analisado foi o depósito por meio da Classificação Internacional de Patentes (conhecida pela sigla IPC - International Patent Classification). A IPC classifica as patentes por área tecnológica $e$ faz com que buscas nas bases patentárias sejam mais ágeis. As seções se dividem em: Seção A - Necessidades humanas; Seção B - Operações de processamento, transporte; Seção C - Química, metalurgia; Seção D - Têxteis, papel; Seção E - Construções fixas; Seção F - Engenharia mecânica, iluminação, aquecimento, armas, explosão; Seção G Física; e Seção H - Eletricidade. Cada seção possui subgrupos, especificando mais cada tema e garantindo uma divisão efetiva.

Os IPCs de interesse que mais apareceram nas tecnologias depositadas foram:

A61Q11/00: Preparações para tratar os dentes, a cavidade oral ou dentaduras, por exemplo, dentifrícios ou pastas de dente; enxaguatórios orais. 
A61P1/02: Fármacos para o tratamento de distúrbios do trato alimentar ou do sistema digestivo. Preparações para distúrbios estomacais, por exemplos, fármacos para cáries, aftas, periodontite.

A61K8/24: Cosméticos ou preparações similares para higiene pessoal, caracterizados pela composição contendo ingredientes inorgânicos. Fósforo; seus compostos.

A61K8/34: Cosméticos ou preparações similares para higiene pessoal, caracterizados pela composição contendo ingredientes inorgânicos, contendo compostos orgânicos, contendo oxigênio, álcoois.

A61K8/9789: Cosméticos ou preparações similares para higiene pessoal, caracterizados pela composição contendo materiais, ou derivados destes, de constituição desconhecida, derivados de algas, líquens, fungos ou plantas; derivados deles, Angiospermas [Magnoliophyta] $e$ Magnoliopsida [dicotyledons].

A61K8/20: Cosméticos ou preparações similares para higiene pessoal, caracterizados pela composição contendo ingredientes inorgânicos halogênios; seus compostos.

A61K8/00: Cosméticos ou preparações similares para higiene pessoal.

A61K8/29: Cosméticos ou preparações similares para higiene pessoal, caracterizados pela composição contendo ingredientes inorgânicos titânio; seus compostos.

A61K8/22: Cosméticos ou preparações similares para higiene pessoal, caracterizados pela composição contendo ingredientes inorgânicos peróxidos; oxigênio; ozônio.

A61K8/35: Cosméticos ou preparações similares para higiene pessoal, caracterizados pela composição contendo compostos orgânicos, contendo oxigênio, cetonas, por exemplo, quinonas, benzofenonas.

A61Q11/02: Preparações para tratar os dentes, a cavidade oral ou dentaduras, por exemplo, dentifrícios ou pastas de dente; enxaguatórios orais. Preparações para desodorizar, clarear ou desinfectar dentaduras.

Gráfico 5 - Classificações Internacional de Patentes (IPCs) que aparecem mais de duas vezes entre os documentos depositados

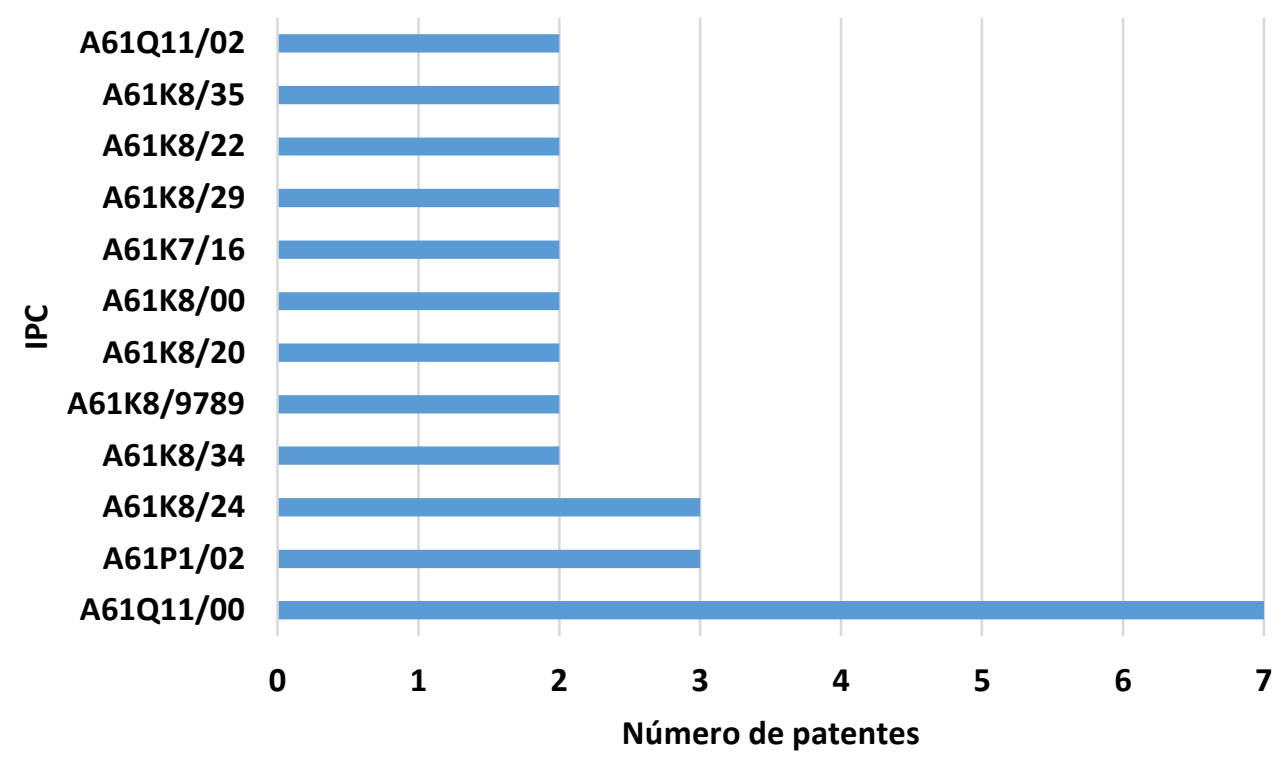

Fonte: Elaborado pelos autores deste artigo 
Pelos resultados, nota-se expressiva diferença entre o número de patentes depositadas com o código A61Q11/00 em relação às demais. Esse IPC se refere a preparações para tratar os dentes, a cavidade oral ou dentaduras, por exemplo, dentifrícios ou pastas de dente; enxaguatórios orais. Ele conta com sete depósitos de patentes.

A segunda posição pertence juntamente aos códigos A61K8/24 - Cosméticos ou preparações similares para higiene pessoal, caracterizados pela composição contendo ingredientes inorgânicos. Fósforo e seus compostos. E também ao A61P1/02 - Fármacos para o tratamento de distúrbios do trato alimentar ou do sistema digestivo, preparações para distúrbios estomacais, por exemplo, fármacos para cáries, aftas, periodontite. Ambos com três patentes cada, ficando longe da primeira posição.

\section{Considerações Finais}

Os resultados ilustram que os maiores cenários sobre enxaguatórios bucais com potencial clareador se localizam nos Estados Unidos e China, pois se destacam em relação aos demais países. No Brasil não foram encontradas patentes relacionadas, refletindo um fraco desempenho em tecnologia.

Lion Corporation e Colgate-Palmolive configuram-se grandes empresas de inovação com relação a esse estudo, porém em outro âmbito, as universidades contam com apenas uma aparição, ficando nítida a necessidade de estímulos.

O mercado está sempre em busca de inovação, e os produtos relacionados a higiene oral não fogem disso. Porém os enxaguatórios bucais com potencial clareador não vêm sendo tão estudados frente ao enorme número de patentes depositadas para produtos de higiene oral como um todo. Com picos e vales de pesquisas relacionadas com o decorrer dos anos, fica claro que um maior número de estudos na área é necessário para a geração de novas tecnologias a serem disponibilizadas comercialmente no mercado.

\section{Agradecimentos}

Os autores agradecem ao CNPq pelo apoio.

\section{Referências}

ABIHPEC - ASSOCIAÇÃO BRASILEIRA DA INDÚSTRIA DE HIGIENE PESSOAL, PERFUMARIA E COSMÉTICOS. Panorama do Setor: higiene pessoal, perfumaria e cosméticos. Relatórios (2008 a 2012). São Paulo: ABIHPEC, 2012.

ABIHPEC - ASSOCIAÇÃO BRASILEIRA DA INDÚSTRIA DE HIGIENE PESSOAL, PERFUMARIA E COSMÉTICOS. ABIHPEC.ORG: Caderno de tendências 2014-2015. [2019]. Disponível em: https://abihpec.org.br/ publicacao/caderno-de-tendencias-2014-2015. Acesso em: 23 jul. 2019. 
ASADOORIAN, J. CDHA position paper on commercially available over-the-counter oral rinsing products. Canadian Journal of dental hygiene (CJDH), [S.l.], v. 40, n. 4, p. 1-13, jul.-aug. 2006. COLGATE-PALMOLIVE. História - Colgate e Palmolive. [2019]. Disponível em: https://www. colgatepalmolive.com.br/about/history. Acesso em: 24 jul. 2019.

EUROMONITOR. Procter \& Gamble Co, The in Consumer Health. 2015.

FDA - FOOD AND DRUG ADMINISTRATION. Part III. Department of health and human services. 21 CFR. Part 356. Oral health care drug products of over the counter human use; antigingivitis / antiplaque drug products; Establishment of a monograph; Proposed rules. Federal Register. v.68, n.103, mai. 2003.

GEBARA, E. C. E.; ZARDETTO, C. G. D. C.; MAYER, M. P. A. Estudo in vitro da ação antimicrobiana de substâncias naturais sobre S.mutans e S. sobrinus. Revista de Odontologia da Universidade de São Paulo, São Paulo, v. 10, n. 4, p. 251-256, out.-dez. 1996.

GHACHACHE, R. Caderno de Tendências 2019-2020. SEBRAE, ABIHPEC, 2019. p. 51.

GURDAL P.; GGNIZ AKDENIZ, B.; HAKAN SEN, B. The effects of mouthrinses on microhardness and color stability of aesthetic restorative materials. J Oral Rehabil, [S.l.], v. 29, n. 9, p. 895-901, 2002 .

JARDIM, P. S.; JARDIM, E. G. J. Influência da remoção mecânica da placa bacteriana associada ao uso diário de solução fluoretada. RGO, Porto Alegre, v. 46, n. 2, p. 79-84, abr.-jun. 1998.

LIFE. LOVE. LION. About us - life: Love. [2019]. Disponível em: https://www.lion.co.jp/en/ company/. Acesso em: 24 jul. 2019.

LIMA JÚNIOR. J. F. et al. O uso de fitoterápicos e a saúde bucal - Phytotherapeutic Agent's Use and Oral Health. Saúde em Revista Piracicaba, [S.l.], v. 7, n. 16, p. 11-17, 2005.

LION CORPORATION. Lion Corporation history. [2019]. Disponível em: http://www. fundinguniverse.com/company-histories/lion-corporation-history/. Acesso em: 24 jul. 2019.

MINTEL. Mercado de enxaguatórios bucais mostra crescimento de 15\% em 5 anos. [2019]. Disponível em: https://www.cosmeticinnovation.com.br/mercado-de-enxaguatorios-bucais-mostracrescimento-de-15-em-5-anos/. Acesso em: $1^{\circ}$ ago. 2019.

NANTONG HONGZHI CHEMICALS CO. LTD. [2019]. Disponível em: http://www.hzpharm.com/ aboute.html. Acesso em: 24 jul. 2019.

PROCTER \& GAMBLE. P\&G- Quem somos. [2019]. Disponível em: https://br.pg.com/o-que-e-pg/. Acesso em: 24 jul. 2019.

SOUZA, F. B.; GIL, J. N. Doença cárie: nem infecciosa, nem transmissível. RGO, Porto Alegre, v. 49, n. 3, p.139-144, jul.-ago. 1998.

TOM's OF MAINE. From our family to yours. [2019]. Disponível em: https://www.tomsofmaine. com/the-backstory. Acesso em: 24 jul. 2019.

TORRES, C. R. G. et al. Agentes antimicrobianos e seu potencial de uso na Odontologia. PGR:

Pós-Grad. R. Odontol., São José dos Campos, v. 2, n. 2, p. 43-52, 2000. 
VALOR ECONÔMICO. Lucro da colgate-palmolive cresce quase $\mathbf{9 0 \%}$ no quarto trimestre.

[2019]. Disponível em: https://www.valor.com.br/empresas/6086495/lucro-da-colgate-palmolive-crescequase-90-no-quarto-trimestre. Acesso em: 24 jul. 2019.

ZANIN, S. M. W. et al. Enxaguatório bucal: principais ativos e desenvolvimento de FÓRMULA contendo extrato hidroalcoólico de Salvia officinalis L. Visão Acadêmica, Curitiba, v. 8, n. 1, jan.jun. 2007.

\section{Sobre os Autores}

\section{Brenda de Oliveira}

E-mail: brendahh.oliveira@gmail.com

Graduanda em Farmácia pela Universidade Federal de Alfenas.

Endereço profissional: Rua Gabriel Monteiro da Silva, n. 700, Centro, Alfenas, MG. CEP: 37130-001.

\section{Mateus Freire Leite}

E-mail: mateus.leite@unifal-mg.edu.br

Doutor em Ciências Farmacêuticas pela Universidade de São Paulo na área de Ciências Farmacêuticas (medicamentos e cosméticos) em em 2009.

Endereço profissional: Rua Gabriel Monteiro da Silva, n. 700, Centro, Alfenas, MG. CEP: 37130-001. 